ORIGINAL ARTICLE

\title{
Prevalence and Predictors of "Small Size" Babies in Ethiopia: In- depth Analysis of the Ethiopian Demographic and Health Survey, 2011
}

\author{
Taddese Alemu ${ }^{1,2}$, Melaku Umeta $^{3}$
}

ABSTRACT

BACKGROUND: Low Birth Weight (LBW) babies account for nearly 80\% of neonatal deaths globally. In Ethiopia, only $5 \%$ of them are weighed at birth. This study analyzes the prevalence and key proximate determinants of reported infant size, and its validity to use as a proxy indicator for low birth weight inthe Ethiopian context.

METHODS: In-depth analysis of the Ethiopian Demographic and Health Survey dataset was conducted using representative data collected from all regions in the country. Considering reported fetal size at birth as an outcome variable, key predicting variables from socio-demographic, household, child and obstetric characteristics were employed for analyses. Chi-square test and multivariate logistic regression model were used to determine predictors at $p$ value $<0.05$.

RESULTS: An average of 29.1\% of Ethiopian babies were reported "small" at birth in 2011. various variables from socio-demographic, household, child and maternal reproductive characteristics were identified as key predictors. Women who develop anemia and not attending antenatal care during pregnancy had $15 \%$ and $41 \%$ more risk of giving birth to the reported "small size" babies than their counterparts $(A o R=1.15$, and $1.41,95 \%$ CI $(1.02,1.64$ and 1.06, 1.88) respectively. Maternal age at delivery, maternal literacy level, paternal educational status and presence of radio or television in the household and other factors were also other key predictors identified.

CONCLUSION: The prevalence of small size babies in Ethiopia is high but comparable to regional estimates of $\mathrm{LBW}$. It is recommend that improving maternal nutritional and socio-economic status is a timely intervention to tackle the problem.

KEYWORDS: Prevalence, Small size, Validity

DOI: http://dx.doi.org/10.4314/ejhs.v26i3.7

\section{INTRODUCTION}

Low birth weight has been defined by the World Health Organization (WHO) as weight at birth of less than 2,500 grams (1). Globally, more than 20 million infants are born with LBW. A larger proportion of them concentrating in Asia and Africa $(2,3)$, LBW babies are more likely to experience physical and developmental health problems or die during the first year of life than are infants of normal weight. It is for this and other reasons that birth weight is considered as the single most important factor affecting neonatal and early neonatal mortality.
LBW is also closely associated with foetal and neonatal morbidity, inhibited growth, cognitive development and chronic diseases in life (2). LBW as indicator is also believed to be a good summary measure of a multifaceted public health problem that includes long-term maternal malnutrition, ill health, hard work and poor pregnancy health care $(2,6)$.

Studies conducted locally and internationally show that conditions including gestational age, maternal age, regular antenatal checkup, mother's height, mother's weight, anemia, physical work, tobacco-chewing and history of abortion are significant determinants of LBW $(7,8)$.

\footnotetext{
${ }^{1}$ Center of Food Science and Nutrition, College of Natural Sciences, Addis Ababa University, Ethiopia.

${ }^{2}$ Dilla University, College of Health and Medicine, and Referal Hospital. P.O.Box, 419, Dilla, Ethiopia.

${ }^{3}$ Department of Medical Biochemistry, College of Health Sciences, Addis Ababa University, Ethiopia.

Corresponding Author: Taddese Alemu, Email: tadal2005@yahoo.com
} 
In Ethiopia, recent estimate (9) shows that the prevalence of low birth weight is $11 \%$ and ranges high up to $28.3 \%$ in some areas (10-12). A hospital based study in North Ethiopia, Gondar (13), found that some $11.2 \%$ of babies were born with LBW, while a similar study in Southwest Ethiopia (Jimma) showed a higher $(22.5 \%)$ prevalence. The other prospective community based study from Eastern (Kersa-Harer) Ethiopia estimated as high as (28.3\%) LBW babies (12).

Though identifying and quantifying determinants of LBW has obtained greater attention, in resource poor settings like Ethiopia, there is critical shortage of consistent and explicit data on the prevalence and its predictors (14). A wise approach to the condition may be the use of alternative proxy indicators.

It is not uncommon to use alternative proxy indicators for measuring health events, during conditions of practical imposibility. For instance, due to the fact that maternal mortality is the worst performing health indicators in resource limmited settings, the WHO uses the study of cases of women who nearly died but survived a complication during pregnancy, childbirth or postpartum (maternal near miss or severe acute maternal morbidity) as useful means to examine quality of obstetric care and evaluation of maternal mortality(15).

Experience from other settings shows that the use of maternal subjective assessment of baby size at birth was found useful predictor of objectively measured birth weight (16). Study from Nepal, a setting similar to Ethiopia, found that mothers' subjective assessments of birth weight had high positive and negative predictive values for LBW. It showed that $92.6 \%$ of the mothers were able to correctly identify whether the child was of average or above size, and six in every ten $(61.3 \%)$ mothers identified that the child was small (16).

This prompts further and in-depth evaluation of the validity of this measure in other similar settings of the developing world, like Ethiopia, where access to vital registration and data on low birth weight are hardly available.

\section{METHODS}

Data source: This study used data from the third round Ethiopian Demographic and Health Survey (EDHS) conducted in 2011. The survey was conducted in all regions of the country with representative samples. The details of the sample design, including the sampling framework and sample implementation and response rates are provided in the respective EDHS reports (www.measuredhs.com).

In the DHS, there are three core questionnaires (Household, Women and a Male questionnaires) and nine recode files. This way of recoding is done because of two outstanding reasons; to define a standardized file that would make cross-country analysis easier and to compare data with the World Fertility Surveys (WFS) to study trends. The recode files have five main and two additional digits. The first two digits of the file name correspond to the country code (e.g. ET for Ethiopia). The next two digits identify the unit of analysis ( IR-Women, KR-Children, ...etc). The fourth digit identifies the DHS phase. The fifth digit identifies the data release number and the last two digits identify whether it is a rectangular (RT) or flat (FL) file; for the hierarchical file they are left blank.

In the current analyses, we used ETKR61FL.SAV recode data files, whereby ET stands for Ethiopia, KR for Kids (children), 6 for the year 2011, FL for flat file) for the analyses of the prevalence and proximate determinants of LBW. This means, we used the 2011 file of children under five to describe the validity, prevalence and key proximate determinants of small size babies in Ethiopia.

Study variables: The dependent variable is prevalence of small size babies at birth. This depends on subjective evaluation of the baby's size at birth by the mother. These potential predicting variables are categorized into four groups: sociodemographic, household, child characteristics and maternal obstetric/reproductive characteristics.

Socio-demographic variables: These groups of indicators consist of maternal socio-demographic characteristics. Among these, maternal age, educational status, literacy level, region, urban/rural residence, wealth status by quintiles are included for analyses.

Household variables: In this group, we included presence or absence of key household goods like electricity, radio, refrigerator, telephone and television. Other variables included in this category are relationship of respondents to the 
household, access to improved toilet facilities and access to safe water supply.

Child characteristics: In this category, we selected child health and related characteristics such as child age, sex, birth weight, level of anemia and birth interval. We also included whether the child is alive or not during the interview and singleton versus twin pregnancy. Maternal reproductive and obstetric variables: In this category, the following variables were included: level of maternal anemia, number of births last year/last five years, knowledge about the reproductive system indicated by awareness of the ovulary cycle. In addtion, other variables like number of living children, history of abortion, history of caesarean delivery, use of alcohol, cigarette/suret and addictive substances during pregnancy were also included.

Data analysis: This study employed a three-stage analysis. Uni-variate and bi-variate analyses were made to calculate validity, prevalence and associations between variables using chi-square, ANOVA and student t-test. Multivariate logistic regression analysis was used for the identification of final predicting variables for small size babies in Ethiopia. STATA 10 and SPSS version 20 softwares were used in both stages of the analysis.

Data quality assessment: The data quality assessment report highlighted its findings on misreporting, omission, and digit preference, which are common data quality problems observed in surveys and censuses in developing countries.

Ethical issues:This is a secondary data analysiss requiring no direct data collection from human subjects. However, request to access datasets from measure DHS website was made, and the websites had allowed the same before analysis was made.

\section{RESULTS}

Data for a total of 11, 872 under five children was abstracted and included to this in-depth analysiss. The maternal reported prevalence of small size babies at birth was $29.1 \%$. Among these, $19.3 \%$ and $12.8 \%$ were reported as "very small" and "small" by their mothers or caretakers, respectively (Figure 1). On the other hand, a larger proportion $(38.4 \%)$ of the babies were reported as "average sized" followed by "very large" (20.6\%).

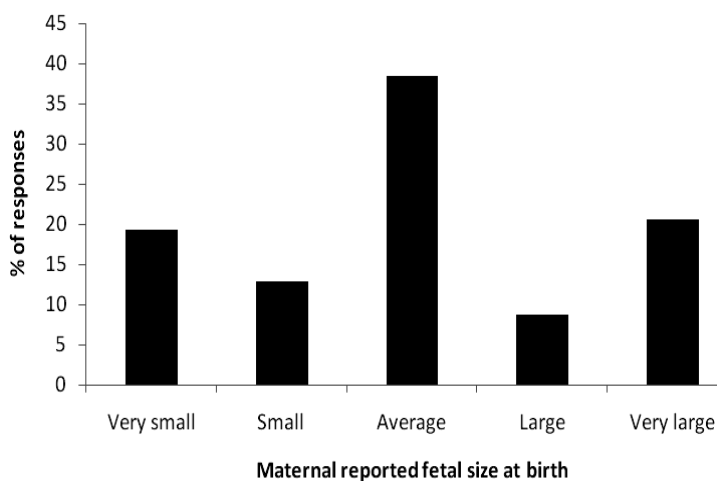

Figure 1 : Reported maternal size of infants at birth for Ethiopian children, EDHS 2011.

Table 1 shows that $68.9 \%$ of the mothers were able to correctly identify if the child was of average size or above. In the same way, more than four in every five $(85.9 \%)$ of the mothers were also corectly reported if the baby was below average size (Table 1).

The prevalence of having small size babies varied inversely and significantly across maternal age groups. As the maternal age group increased from 15-19 to 45-49, the risk of having small size babies declined ( $\mathrm{p}<0.05)$ (Table 2).

Table 1: Test of concordance between the reported size at birth and recorded birth weight, EDHS 2011

\begin{tabular}{lcc}
\hline & \multicolumn{2}{c}{ Birth weight of the child } \\
Maternal subjective report of size at birth & $<2500$ & $\geq 2500$ \\
\hline $\begin{array}{l}\text { Greater than equal to average } \\
\quad \text { (Average, large and very large) }\end{array}$ & 14.1 & 68.9 \\
$\begin{array}{l}\text { Small size babies } \\
\text { (Very small and small) }\end{array}$ & 85.9 & 31.1 \\
\hline
\end{tabular}


Table 2: Determinants of small size babies by selected maternal socio-demographic characteristics, in Ethiopia, EDHS 2011.

\begin{tabular}{|c|c|c|c|c|}
\hline \multirow[b]{2}{*}{$\begin{array}{l}\text { Socio-demographic } \\
\text { Characteristic }\end{array}$} & \multicolumn{2}{|c|}{ Baby Size at Birth } & \multirow[b]{2}{*}{$\begin{array}{c}\text { Crude OR } \\
(95 \% \mathrm{CI})\end{array}$} & \multirow[b]{2}{*}{$\begin{array}{l}\text { Adjusted OR } \\
(95 \% \mathrm{CI})\end{array}$} \\
\hline & $\begin{array}{l}\text { Small } \\
\text { No }(\%)\end{array}$ & $\begin{array}{c}\text { Non- Small } \\
\operatorname{No}(\%)\end{array}$ & & \\
\hline \multicolumn{5}{|l|}{ Maternal Age } \\
\hline $15-19$ & $182(37)$ & $310(63)$ & 1 & 1 \\
\hline $20-24$ & $782(33.8)$ & $1544(66.2)$ & $0.94(0.83,1.05)$ & $0.94(0.76,1.16)$ \\
\hline $25-29$ & $1042(27.5)$ & $2743(72.5)$ & $0.78(0.70,0.88)$ & $0.70(0.57,0.86)^{*}$ \\
\hline $30-34$ & $626(26.8)$ & $1710(73.2)$ & $0.78(0.71,0.88)$ & $0.64(0.52,0.79) *$ \\
\hline $35-39$ & $526(28.9)$ & $1292(71.1)$ & $0.78(0.69,0.89)$ & $0.72(0.58,0.79)^{*}$ \\
\hline $40-44$ & $227(29.4)$ & $546(70.6)$ & $0.85(0.74,0.94)$ & $0.68(0.53,0.87) *$ \\
\hline $45-49$ & $73(26.8)$ & $199(73.2)$ & $0.90(0.76,1.07)$ & $0.62(0.44,0.86)^{*}$ \\
\hline \multicolumn{5}{|l|}{ Residence } \\
\hline Urban & $367(24.3)$ & $1146(75.7)$ & 1 & 1 \\
\hline Rural & $3101(30.1)$ & 7207 (69.9) & $1.43(1.32,1.55)$ & $1.32(1.13,1.54)^{*}$ \\
\hline \multicolumn{5}{|l|}{ Region } \\
\hline Tigray & $240(32)$ & $510(68)$ & 1 & 1 \\
\hline Afar & $49(40.5)$ & $72(59.5)$ & $1.65(1.32,2.06)$ & $0.90(0.62,1.32)$ \\
\hline Amhara & $1067(40.4)$ & $1574(59.6)$ & $1.19(1.08,1.32)$ & $1.20(0.72,1.98)$ \\
\hline Oromia & $1301(26.1)$ & $3691(73.9)$ & $0.75(0.68,0.82)$ & $1.23(0.86,1.76)$ \\
\hline Somali & $121(33.2)$ & $243(66.8)$ & $0.79(0.67,0.94)$ & $0.67(0.47,0.95) *$ \\
\hline Beng. Gumuz & $34(24.5)$ & $105(75.5)$ & $0.78(0.61,1.08)$ & $1.00(0.67,1.53)$ \\
\hline SNNPR & $568(22.8)$ & $1920(77.2)$ & $0.65(0.59,0.73)$ & $0.63(0.37,1.07)$ \\
\hline Gambella & $13(32.5)$ & $27(67.5)$ & $0.72(0.46,1.13)$ & $0.58(0.40,0.83)^{*}$ \\
\hline Hareri & $8(28.6)$ & $20(71.4)$ & $0.70(0.42,1.17)$ & $1.03(0.46,2.32)$ \\
\hline Addis Ababa & $55(25.1)$ & $164(74.9)$ & $0.63(0.51,0.78)$ & $0.86(0.35,2.12)$ \\
\hline Dire Dawa & $11(28.9)$ & $27(71.1)$ & $0.69(0.45,1.06)$ & $0.87(0.39,1.94)$ \\
\hline \multicolumn{5}{|l|}{ Maternal Educ. Status } \\
\hline No Education & 2585 (31.6) & $5603(68.4)$ & 1 & 1 \\
\hline Prim. Education & $796(24.8)$ & $2419(75.2)$ & $0.75(0.71,0.80)$ & $0.95(0.83,1.08)$ \\
\hline Sec. Education & $62(23.6)$ & $201(76.4)$ & $0.57(0.49,0.65)$ & $1.04(0.71,1.52)$ \\
\hline Higher Education & $26(15.8)$ & $139(84.2)$ & $0.42(0.29,0.59)$ & $0.76(0.48,1.27)$ \\
\hline \multicolumn{5}{|l|}{ Maternal Literacy level } \\
\hline Can't read/write & $2849(31)$ & $6384(69)$ & 1 & 1 \\
\hline $\mathrm{R} \& \mathrm{~W}$ (partial) & $255(23.7)$ & $819(76.3)$ & $0.82(0.75,0.89)$ & $0.81(0.68,0.94)^{*}$ \\
\hline R \& W (Fully) & $326(23.5)$ & $1064(76.5)$ & $0.68(0.63,0.74)$ & $0.78(0.64,0.95)^{*}$ \\
\hline \multicolumn{5}{|l|}{ Wealth Index } \\
\hline Poorest (Q1) & $938(34.7)$ & $1762(65.3)$ & 1 & 1 \\
\hline Poor (Q2) & $774(29.3)$ & $1866(70.7)$ & $0.78(0.69,0.87)$ & $0.65(0.34,0.04)^{*}$ \\
\hline Average (Q3) & $778(32)$ & $1655(68)$ & $0.88(0.78,0.99)$ & $0.35(0.09,0.65)^{*}$ \\
\hline Rich (Q4) & $581(25.7)$ & $1684(74.3)$ & $0.65(0.57,0.73)$ & $0.58(0.27,0.95)^{*}$ \\
\hline Richest (Q5) & $397(22.3)$ & $1386(77.7)$ & $0.54(0.47,0.62)$ & $0.22(0.00,0.50 *$ \\
\hline Total & $3468(29.3)$ & $8353(70.7)$ & & \\
\hline
\end{tabular}

**statistically significant $(\mathrm{P}<0.001)$

Intermes of the maternal residential area, more mothers from the rural as compared to the urban settings reported a more $(32 \%)$ risk of small size babies (AoR, 1.32; 95\% CI, 1.13 -1.54). Similarly, having small size babies also varied across all regions in the country, although not statistically significant differences, except for Gambella and Somali regions. Compared to Tigray, mothers in these regions reported a $42 \%$ and $33 \%$ less risk $($ AoR $=0.58,95 \%$ CI, $(0.40,0.83)$ and AoR $=$ $0.67,95 \%$ CI $(0.47,0.95))$ of small size babies respectively (Table 2 ).
Maternal literacy level, not educational status, was also statistically associated with the size of babies at birth in Ethiopia. As the maternal literacy level improved from none to partially or fully able to read and write, the probability of having small size babies significantly declined by $19 \%$ and $22 \%$ $($ AoR $=0.81$ and $0.78 ; 95 \% \mathrm{CI},(0.68,0.94)$ and $(0.64,0.95))$ respectively.

Regarding the household income (wealth status), an inverse but significant association was observed with giving birth to small size babies, which is a proxy indicator for LBW babies; i.e. the 
better the wealth status of the household, the lesser the risk of having small size babies. Compared to the poorest $\left(\mathrm{Q}_{1}\right)$, mothers from the poor $\left(\mathrm{Q}_{2}\right)$, the middle $\left(\mathrm{Q}_{3}\right)$, the rich $\left(\mathrm{Q}_{4}\right)$ and the richest $\left(\mathrm{Q}_{5}\right)$ household reported a $35 \%$ (AoR, 0.65; 95\% CI, 0.34 - 0.04), 65\% (AoR, o,35; 95\% CI, 0.09$0.65), 32 \%(A o R, 0.58 ; 95 \%$ CI $0.27-0.95)$ and $78 \%$ (AoR, 0.22; 95\% CI 0.00 -0.50) less risk of small sized babies at birth respectively (Table 2 ).

Table 3 presents the household variables analyzed for any potential association with infant size at birth. Accordingly, ownership of radio and television were among the factors that had statistically significant association with the outcome variable of interest. Thus, families owning radio and television had a 26\% (AoR, 1.26; 95\% CI, 1.12 - 1.41) and a 2.05 fold (AoR, $2.05 ; 95 \% \mathrm{CI}, 1.41,2.96)$ increased risk of giving a small size babies than those who have neither. Although household variables like presence of electricity, ownership of refrigerator and access to safe water source or sanitation had varied risk level for small size babies, none of the appeared in the final logistic regression model.

Table 3: Prevalence and determinants of small size babies by selected household characteristics in Ethiopia, EDHS 2011

\begin{tabular}{|c|c|c|c|c|}
\hline \multirow{2}{*}{$\begin{array}{l}\text { House-hold } \\
\text { Characteristic }\end{array}$} & \multicolumn{2}{|c|}{ Baby Size at Birth } & \multirow{2}{*}{$\begin{array}{c}\text { Crude OR } \\
(95 \% \mathrm{CI})\end{array}$} & \multirow{2}{*}{$\begin{array}{l}\text { Adjusted OR } \\
(95 \% \mathrm{CI})\end{array}$} \\
\hline & $\begin{array}{l}\text { Small } \\
\text { No( } \%)\end{array}$ & $\begin{array}{l}\text { Non- Small } \\
\operatorname{No}(\%)\end{array}$ & & \\
\hline \multicolumn{5}{|c|}{ Electricity in the $\mathrm{HH}$} \\
\hline No & 3009 (30.3) & $6936(69.7)$ & 1 & 1 \\
\hline Yes & $345(22.8)$ & $1196(77.2)$ & $1.55(1.42,1.69)$ & $1.02(0.81,1.27)$ \\
\hline \multicolumn{5}{|l|}{ Radio in the $\mathrm{HH}$} \\
\hline No & $2223(31.8)$ & $4776(68.2)$ & 1 & 1 \\
\hline Yes & $1140(25.4)$ & $3356(74.6)$ & $1.29(1.23,1.36)$ & $1.26(1.12,1.41)^{*}$ \\
\hline \multicolumn{5}{|c|}{ Television in the $\mathrm{HH}$} \\
\hline Yes & $3233(29.9)$ & $7597(70.1)$ & 1 & 1 \\
\hline No & $130(19.7)$ & $529(80.3)$ & $1.98(1.68,2.32)$ & $2.05(1.41,2.96) *$ \\
\hline \multicolumn{5}{|l|}{ Water Source } \\
\hline Unsafe & $1167(27.5)$ & $3083(72.5)$ & 1 & 1 \\
\hline Safe & $2186(30.4)$ & $5007(69.5)$ & $1.11(0.98,1.25)$ & $1.11(0.98,1.25)$ \\
\hline Sanitation facility & & & 1 & 1 \\
\hline Improved & $1573(31.6)$ & $3410(68.4)$ & $0.99(0.86,1.16)$ & $0.99(0.86,1.16)$ \\
\hline Non-improved & $385(26.9)$ & $1045(73.1)$ & & \\
\hline Total & $3353(29.3)$ & $8990(70.7)$ & & \\
\hline
\end{tabular}

*statistically significant

From child related characteristics/variables analyzed, the objectively measured birth weight appeared to be strongly associated with maternal the subjective evaluation of birth size at birth. Infants born with a birth weight of low $(<2.5 \mathrm{~kg})$ were 12.09 times more likely to be correctly and validly reported the same by their mothers or care takers during the survey compared to those above $2.5 \mathrm{~kg}$ (AoR, 12.09; 95\% CI, $(8.59,17.02)$. Other variables in this category like child's sex, preceding birth interval, child's survival status (alive or dead) and twin birth were all eliminated in the final model (Table 4).
Among the maternal obstetric and reproductive characteristics included in the current analysis, anemia during pregnancy and antenatal care followup were found to be independent and useful predictors of having small size babies by mothers. Anemic mothers whose hemoglobin level was $<11$ during pregnancy had $15 \%$ more risk of giving small sized babies (AoR, 1.15; 95\% CI, 1.021.64) than non-anemic mothers. In the same way, pregnant women not attending antenatal care (ANC) reported $40 \%$ higher risk of small size babies than the those who attended at least once during the immediate pregnancy (AoR, 1.41; 95\% CI, 1.06-1.88) (Table 5). 
Table 4: Prevalence and determinants of small size babies by selected Child characteristics in Ethiopia, EDHS , 2011

\begin{tabular}{|c|c|c|c|c|}
\hline \multirow[t]{2}{*}{ Child Characteristics } & \multicolumn{2}{|c|}{ Baby Size at Birth } & \multirow{2}{*}{$\begin{array}{c}\text { Crude OR } \\
(95 \% \mathrm{CI})\end{array}$} & \multirow{2}{*}{$\begin{array}{c}\text { Adjusted OR } \\
\text { (95\% CI) }\end{array}$} \\
\hline & $\begin{array}{l}\text { Small } \\
\text { No(\%) }\end{array}$ & $\begin{array}{l}\text { Non- Small } \\
\text { No( \%) }\end{array}$ & & \\
\hline \multicolumn{5}{|l|}{ Sex of the Child } \\
\hline Male & $1576(25.7)$ & $4560(74.3)$ & 1 & 1 \\
\hline Female & $1892(33.3)$ & $3793(66.7)$ & $1.52(1.45,1.59)$ & $2.14(0.27,16.57)$ \\
\hline \multicolumn{5}{|l|}{ Child's Birth weight } \\
\hline$<2500 \mathrm{~g}$ & $62(45.3)$ & $75(54.7)$ & 1 & 1 \\
\hline$\geq 2500 \mathrm{~g}$ & $28(5.8)$ & $456(94.2)$ & $12.09(8.59,17.02)$ & $12.09(8.59,17.02) *$ \\
\hline \multicolumn{5}{|l|}{ Preceding birth interval } \\
\hline$<12$ months & $64(29.9)$ & $150(70.1)$ & 1 & 1 \\
\hline $12-23$ months & $477(27.3)$ & $1269(72.7)$ & $0.77(0.65,0.91)$ & $0.20(0.002,21.7)$ \\
\hline $24-35$ months & $914(26.9)$ & $2482(73.1)$ & $0.82(0.69,0.96)$ & $0.28(0.00,14.91)$ \\
\hline 36 - 47 months & $635(28.9)$ & $1564(71.1)$ & $0.89(0.76,1.05)$ & $2.08(0.04,120)$ \\
\hline $48-59$ moths & $270(28.5)$ & $679(71.5)$ & $0.90(0.76,1.07)$ & $0.44(0.00,36.5)$ \\
\hline$\geq 60$ months & $329(31)$ & $732(69)$ & $0.84(0.70,1.00)$ & $0.01(0.00,20.26)$ \\
\hline \multicolumn{5}{|l|}{ Child's status } \\
\hline Dead & $194(24.3)$ & $606(75.8)$ & 1 & 1 \\
\hline Alive & $3275(29.7)$ & $7747(70.30$ & $1.20(1.11,1.30)$ & $1.10(0.01,97.9)$ \\
\hline Total & $3353(29.3)$ & $8990(70.7)$ & & \\
\hline
\end{tabular}

*statistically significant

Table 5: Prevalence and Determinants of Small Size Babies by Selected Maternal Obstetric and Reproductive Characteristics in Ethiopia, EDHS, 2011

\begin{tabular}{|c|c|c|c|c|}
\hline \multirow{2}{*}{$\begin{array}{l}\text { Maternal Reproductive \& } \\
\text { Obstetric Characteristic }\end{array}$} & \multicolumn{2}{|c|}{ Baby Size at Birth } & \multirow{2}{*}{$\begin{array}{c}\text { Crude OR } \\
(95 \% \text { CI })\end{array}$} & \multirow{2}{*}{$\begin{array}{l}\text { Adjusted OR } \\
(95 \% \mathrm{CI})\end{array}$} \\
\hline & $\begin{array}{l}\text { Small } \\
\text { No(\%) }\end{array}$ & $\begin{array}{l}\text { Non- Small } \\
\text { No( } \%)\end{array}$ & & \\
\hline \multicolumn{5}{|l|}{ Anemia During pregnancy } \\
\hline No & $2690(29.1)$ & $6560(70.9)$ & 1 & 1 \\
\hline Yes & $692(31.7)$ & $1493(68.3)$ & $1.29(1.02,1.64)$ & $1.1(1.02,1.64) *$ \\
\hline \multicolumn{5}{|l|}{ Ever had terminated pregnancy } \\
\hline No & $3082(29.1)$ & $7513(70.9)$ & 1 & 1 \\
\hline Yes & $386(31.5)$ & $840(68.5)$ & $1.05(0.98,1.13)$ & $1.07(0.73,1.56)$ \\
\hline \multicolumn{5}{|l|}{ Current pregnancy wanted } \\
\hline Yes (Then or latter) & $286(27.2)$ & $764(72.8)$ & 1 & 1 \\
\hline No & $32(21.3)$ & $118(78.7)$ & $1.05(0.98,1.13)$ & $0.72(0.52,1.14)$ \\
\hline \multicolumn{5}{|l|}{ ANC visit during pregnancy } \\
\hline No & $1523(33.9)$ & $2971(66.1)$ & 1 & 1 \\
\hline Yes & $1946(26.6)$ & $5382(73.4)$ & $1.32(1.25,1.41)$ & $1.41(1.06,1.88)^{*}$ \\
\hline \multicolumn{5}{|l|}{ Had Previous C/Section } \\
\hline No & $3434(29.5)$ & $8213(70.5)$ & 1 & 1 \\
\hline Yes & $34(19.5)$ & $140(80.5)$ & $1.69(1.32,2.19)$ & $0.1(0.002,8.96)$ \\
\hline
\end{tabular}

*statistically significant

\section{DISCUSSION}

Globally, over 58\% of newborn infants are not weighed, and in Ethiopia it peaks as high as 95\% (14,16). It will be a misleading evidence to measure the prevalence and incidence of low birth weight babies using this kinds of non-representative (only 5\%) of the measured birth weight depending on institutional data alone. Evaluating an alternative proxy indicator like mothers' subjective assessmenst of the size of babies at birth may be useful. Previous experiences from other low income countries across the globe, Nepal for example $(16,17)$, shows that mothers were able to detect as high as $61.3 \%$ of low 
birth weight and $92.6 \%$ of non-low birth weights correctly.(15). In a very closer reporting, our currently analyzes showed that, Ethiopian women were also able to correctly report $68.9 \%$ of the non-low birth weight and $85.6 \%$ of the low birth weight infants, just considering only the $5 \%$ weighed babies at birth (18).

It was also learned that closer to the reports of other similar local studies $(5,11,14,19)$, the overall prevalence of low birth weight (small size babies, in this case) has significantly declined from $33.4 \%$ to $27.9 \%$ and $29.3 \%$ between 2000 and 2011 (20,21). On the other hand, the level of the prevalence of small size babies is by far higher than the recorded low birth weight babies. For instance, in 2011, mothers reported that $29.3 \%$ of their babies were small in size as compared to only $11 \%$ of recorded low birth weight during the same period. This is mainly attributable to the fact that most of the small size babies are not reported to health systems as the overall institutional delivery is very small, and recording of vital events in the nation is very poor (14).

The above findings are consistent with other studies in the country conducted using actual birth weight data from the community setting within 24 hours (12). According to Nega et.al (12), using a data collected from the community setting, a figure $(28.3 \%)$ closer to the reported than to the recorded prevalence of low birth weight is obtained. This signifies that, in resource limmitted settings like Ethioia, maternal subjective assesment of birth size is found useful and relatively reliable.

Among the key predictors of small size babies, maternal age, urban-rural residence, region, maternal literacy level and household wealth index (status) were among the socio-demographic characteristics which had association with the outcome variable under investigation. According to the responding mothers, risk of giving small size baby inversely decreased with increased maternal age, literacy level and wealth index. The same also diminishes for urban mothers by $32 \%$ as compared to their rural counterparts. This finding is concurrent to several other studies conducted locally (12) and internationally $(23,24)$.

In the same way, access to media (ownership of electronics like radio or television) in the household are also associated with risk of small sized babies in the Ethiopian context. Access to mass media (radio and television) provides mothers with information on the benefits of pregnancy and child care services. This will enhance the health status of the unborn baby and in turn increases the demand for reproductive health services. Mothers from a household without a radio or a television reported a $26 \%$ and a twofold added risk of delivering small size babies (AoR $=1.26$ and 2.05, 95\% $\mathrm{CI}=(1.12,1.41)$ and $(1.41,2.96)$ respectively. This finding is also conisitent with the findings of other studies conducted in Africa and elsewhere $(25,26)$.
A low birth weight child was seen to be12.09 times more likely and accurately to be reported as small size by mothers. This reproves the fact mentioned above that in the absence of measured birth weight, maternal estimate for the size of the baby is more likely to be consistent with the objective measure by baby scale. A similar finding is also obtained elsewhere (16).

Mothers who became anemic during their last pregnancy and those who didn't have any ANC followup had a $15 \%$ and $41 \%$ added risk of having small size babies $($ AoR $=1.15,95 \%$ CI $(1.02,1.64)$ and 1.41(1.06, 1.88). This is consistent with several other findings $(2,4,12,13,27,28)$ in that maternal nutritional condition in general and anemia during pregnancy as well as antenatal care followup during pregnancy are conclusively identified as being among the most important factors determining fetal size at birth or birth weight.

Generally, the national prevalence of LBW babies, as indicated here by reported small size, is high and comparable to findings of local studies. Promisingly, it has also showed a declining trend between 2000 - 2011. Yet, huge discrepancy between findings of institution based studies and the current reported birth weight as well as other cross-sectional community based studieswas also observed. Results of the community based cross-sectional surveys at grass root (community) level reported a more closer value to the maternal subjective reports. This was mainly explained by variables from household, socio-demographic, child as well as maternal reproductive and obstetric sources.

Therefore, it is recommended that public health measures mitigating low birth weight in Ethiopia. Furthermore, in resource limited settings like Ethiopia, where measuring birth weight is expensive and hardly possible, it is useful to use maternal subjective reports of infant size at birth, rather than relying only on facility based records.

\section{REFERENCES}

1. Avery ME, Tooley WH, Keller JB, et al. Is chronic lung disease in low birth weight infants preventable? A survey of eight centers. Pediatrics. 1987;79(1):2630.

2. Wardlaw TM, editor. Low birthweight: country, regional and global estimates. UNICEF; 2004.

3. Potdar RD, Sahariah SA, Gandhi M, et al. Improving women's diet quality preconceptionally and during gestation: effects on birth weight and prevalence of low birth weight - a randomized controlled efficacy trial in India (Mumbai Maternal Nutrition Project). Am J Clin Nutr, 2014 Nov 1;100(5):1257-68. 
4. Kramer MS. Determinants of low birth weight: methodological assessment and meta-analysis. Bulletin of the WHO. 1987;65(5):663.

5. Gebremariam A. Factors predisposing to low birth weight in Jimma Hospital south western Ethiopia. East Afr Med J. 2005 Nov 1;82(11):554.

6. Hack M, Flannery DJ, Schluchter M, Cartar L, Borawski E, Klein N. Outcomes in young adulthood for very-low-birth-weight infants. New England Journal of Medicine. 2002;346(3):149-57.

7. Khalidi N, McGill K, Houweling H, Arnett K, Sheahan A. Closing the Gap in Low Birthweight Births between Indigenous and Non-- Indigenous Mothers, Queensland. Brisbane: Health Statistics Unit. 2012.

8. Agarwal K, Agarwal A, Agrawal VK, Agrawal P, Chaudhary V. Prevalence and determinants of" low birth weight" among institutional deliveries. Annals of Nigerian Medicine. 2011;5(2):48.

9. Viengsakhone L, Yoshida Y, Sakamoto J. Factors affecting low birth weight at four central hospitals in vientiane, Lao PDR. Nagoya journal of medical science. 2010;72(1-2):51-8..

10. Patel D, Vaghasiya J, Pancholi SS, Paul A. Therapeutic potential of secoisolariciresinol diglucoside: a plant lignan. International Journal of Pharmaceutical Sciences and Drug Research. 2012;4(1):15-8..

11. Tema T. Prevalence and determinants of low birth weight in Jimma Zone, Southwest Ethiopia. East Afr Med J.2006 Jul 1;83(7):366.

12. Assefa N, Berhane Y, Worku A. Wealth status, mid upper arm circumference (MUAC) and antenatal care (ANC) are determinants for low birth weight in Kersa, Ethiopia. PloS one. 2012;7(6):e39957.

13. Adane AA, Ayele TA, Ararsa LG, Bitew BD, Zeleke BM. Adverse birth outcomes among deliveries at Gondar University Hospital, Northwest Ethiopia. BMC pregnancy and childbirth. 2014;14(1):1.

14. CSA I. Ethiopia demographic and health survey 2011. Addis Ababa, Ethiopia and Calverton, Maryland, USA: Central Statistical Agency and ICF International. 2012.

15. Say L, Souza JP, Pattinson RC. Maternal near misstowards a standard tool for monitoring quality of maternal health care. Best Practice \& Research Clinical Obstetrics \& Gynaecology. 2009 Jun 30;23(3):287-96.

16. Khanal V, Sauer K, Karkee R, Zhao Y. Factors associated with small size at birth in Nepal: further analysis of Nepal Demographic and Health Survey 2011. BMC pregnancy and childbirth. 2014;14(1):1.
17. Ndu IK, Ibeziako SN, Obidike EO, Adimora GN, et al. Chest and occipito-frontal circumference measurements in the detection of low birth weight among Nigerian newborns of Igbo ethnicity. Italian journal of pediatrics. 2014;40(1):1-8.

18. Joshi C, Torvaldsen S, Hodgson R, Hayen A. Factors associated with the use and quality of antenatal care in Nepal: a population-based study using the demographic and health survey data. BMC pregnancy and childbirth. 2014;14(1):1.

19. CSA-Ethiopia, I.C.F., 2012. International: Ethiopia Demographic and Health Survey 2011. Central Statistical Agency of Ethiopia and ICF International Addis Ababa, Ethiopia and Calverton, Maryland, USA

20. Ethiopia MO. Evaluation report of the implementation of the 2000-2004 Integrated Disease Surveillance and Response (IDSR) initiative in Ethiopia.

21. Demographic CS. Health Survey, Addis Ababa. Ethiopia: Central Statistics Authority. 2000.

22. Lakew Y, Biadgilign S, Haile D. Anaemia prevalence and associated factors among lactating mothers in Ethiopia: evidence from the 2005 and 2011 demographic and health surveys. BMJ open. 2015 Apr 1;5(4):e006001.

23. Zeleke BM, Zelalem M, Mohammed N. Incidence and correlates of low birth weight at a referral hospital in Northwest Ethiopia. Pan Afr Med J, 2012;12(1):4.

24. School TO, Hediger ML, Fischer RL, Shearer JW. Anemia vs iron deficiency: increased risk of preterm delivery in a prospective study. The Am J Clin Nutr, 1992;55(5):985-8.

25. Sturley J, Burke S, Balanda K. Unequal at Birth: Inequalities in the occurrence of low birthweight babies in Ireland. Institute of Public Health in Ireland; 2006.

26. Asekenye LBMLO. The determinants of birthweight in Uganda. Nairobi University; 2009. p. 1-31.

27. Okurut Francis Nathan. Determinants of birth weight in Botswana. PhD Thesis. 2009:1-17.

28. Ohlsson A, Shah P. Determinants and Prevention of Low Birth Weight: A Synopsis of the Evidence. Alberta Canada; 2008.

29. Gebremedhin S, Samuel A, Mamo G, Moges T, Assefa T. Coverage, compliance and factors associated with utilization of iron supplementation during pregnancy in eight rural districts of Ethiopia: a cross-sectional study. BMC Public Health. 2014;14(1):607. 